\title{
KNOWLEDGE ON MENSTRUAL HYGIENE AMONG RESIDENTIAL AND NON- RESIDENTIAL SCHOOL GIRLS
}

\author{
KRUTIKA CHANDA \& SUNANDA ITAGI
}

Department of Human Development and Family Studies College of Rural Home Science,

University of Agriculture Science, Dharwad, India

\begin{abstract}
Menstruation is one such natural phenomenon which is an important indicator of women's health. The name menstruation" comes from the Latin "menses" meaning moon, with reference to the lunar month and lasting also approximately 28 days long. Menstruation has always been surrounded by different perceptions throughout the world due to which even after the attainment of menarche, very little information is given to young girls about hygienic practices to be followed. Thus, present study was conducted to explore the menstrual hygiene among residential and non-residential school age girls with the following aim to know the level of knowledge regarding menstrual hygiene among residential and non-residential school girls. The sample consists of 60 each residential and non-residential school from rural and urban areas of Dharwad taluk during 2014-2015. The tools used for the study were the selfstructured questionnaire, to elicit the information regarding knowledge and practice of menstrual hygiene during menstruation among girls and Socio-Economic Status Scale developed by Agarwal et al, (2005). The results indicated that there was no difference, but significant association found between the residential and non-residential school girls in case of knowledge on menstrual hygiene, while none of the girls had low knowledge. Mother was the major source of informant in both residential and non-residential school girls. The frequency of changing pad was more than three times and stomach ache was the major problem faced by the girls. Majority of the girls from residential and non-residential school did not miss the classes while few took rest during their periods. While majority of them followed proper method of disposal of both cloth as well as sanitary pads. Hence, this is a good indicator of improvement in the hygienic practices among the school girls.
\end{abstract}

KEYWORDS: Menstruation, Knowledge Regarding Menstrual Hygiene and Practices

Received: Jun 25, 2017; Accepted: Jul 14, 2017; Published: Jul 20, 2017; Paper Id.: IJESRAUG20178

\section{INTRODUCTION}

The World Health Organization (WHO) has defined adolescence as the age group of 10-19 years. Adolescents stand at the crossroads between childhood and the adult world. Where during this period between childhood and young adulthood is a period of rapid change - physical, emotional, cognitive and social? For girls, we see early physical changes from about 10 or 11 years. Menstruation is one such natural phenomenon which is an important indicator of women's health. Although menstruation is a major significant event associated with bodily changes with hormones, psychological, cognitive and physical changes occur simultaneously and interactively making physiological development a challenge adolescents have to face, with emotional, social and behavioral dimensions.

The name menstruation" comes from the Latin "menses" meaning moon, with reference to the lunar month and lasting also approximately 28 days long. The menstrual cycle is the cycle of natural changes that occurs 
in the uterus and ovary as an essential part of making sexual reproduction possible. Its timing is governed by endogenous (internal) biological cycles. The menstrual cycle is essential for the production of ova and for the preparation of the uterus for pregnancy. The cycle occurs only in fertile female humans and other female primates. In human females, the menstrual cycle occurs repeatedly between the ages of menarche, when cycling begins, until menopause, when it ends.

The length of a menstrual cycle varies greatly among women (ranging from 21 to 35 days), with 28 days designated as the average length. Each cycle can be divided into three phases based on events in the ovary (ovarian cycle) or in the uterus (uterine cycle).

Menstruation has always been surrounded by different perceptions throughout the world. Nowadays, there is some openness toward menstruation, but differences in attitude still persist between different populations, while menstruation is still related to a number of cultural taboos as well as feelings of shame and uncleanliness. Even today menstruation is a secret of mother and daughter in many families. There are many taboos like menstruating girl is prevented from going to temple, to cook food, to attend weddings, etc. There is limited knowledge and many misconceptions about menstruation among young women in India before and even after the menarche. This usually leads to undue fear, anxiety and undesirable practices. Even after the attainment of menarche, very little information is given to young girls about the physiological processes involved and the hygienic practices to be followed.

Hence, targeting school girls at the time of adolescence is an appropriate strategy, since it is the time when most of them are curious about their bodily changes and also active learning phase takes place. During these formative years which reflect future health of adolescence, hygienic care revolving around the menstrual cycle needs to be addressed and emphasis on healthcare is essential to shape their quality of life in the years to come. Thus, present study was conducted to explore the menstrual hygiene among residential and non-residential school age girls with the following objectives to know the level of knowledge regarding menstrual hygiene among residential and non-residential school girls.

\section{MATERIALS AND METHODS}

The study was conducted in the year 2014-15 using differential research design to know the difference in level of knowledge among residential and non- residential school girls in Dharwad district, Karnataka state. The list of schools in Dharwad district was obtained from Block Education Officer. The principal of the school was approached for permission to conduct the research. Girls in the age group of 13-16 years studying in 8th and 9th standards from two residential and non-residential schools from rural and urban areas were selected randomly. Among each school 15 girl students were selected from the above selected age group based on the criteria that they should have attained menarche before one year for assessing their knowledge, practice, menstrual hygiene regarding menstruation. Hence the finial samples for the study were 60 residential and 60 non-residential school girls.

The Socio economic status of the family was assessed using socio- economic scale developed by Agarwal et al. (2005).A self-structured questionnaire was used to elicit the information regarding knowledge and practice of menstrual hygiene during menstruation among girls.(reliability and validity of the tool 0.97) This tool consists of 36 questions divided into six categories like general information, school facility and information, history of menstruation, effects of menstruation, care and management of menstruation and myths and taboos.

\section{RESULTS AND DISCUSSIONS}

The Table 1 indicates knowledge on menstrual hygiene of school age girls where it is important to note that 
among residential school girls, 45 per cent girls have medium knowledge on menstrual hygiene and 55 per cent girls indicated high knowledge on menstrual hygiene. Whereas from the non-residential school girls 36.67 per cent showed medium knowledge and remaining 63.33 per cent girls had high knowledge on menstrual hygiene. The non-residential (56.18 \pm 2.54$)$ girls mean was slightly higher than the residential $(55.71 \pm 3.48)$ school girls. There was no difference and significant association found between the residential and non-residential school girls in case of knowledge on menstrual hygiene. A study by Chanda et al. (2016) indicated that there was highly significant difference found between rural and urban areas with knowledge on menstrual hygiene, rural and urban areas with residential and non-residential school, knowledge on menstrual hygiene with age and rural and urban areas with age with component of knowledge on menstrual hygiene with age and with residential and non-residential schools.

Table 2 indicate that girls response towards awareness regarding menstruation before menarche indicated that 60 per cent had awareness and 40 per cent were unaware of menstruation in residential school girls while from the non residential school 55 per cent girls were aware and remaining 45 per cent were unaware of menstruation before menarche. A study by Chanda and Itagi (2016) similar results on level of knowledge of menstrual hygiene. The major source of informant was found to be the mother $(71.66 \%$ and $63.33 \%)$ than followed by elder sister $(28.33 \%$ and $36.67 \%)$ in residential and non- residential school girls. None of them received information regarding menstruation from teachers, friends, media and books and magazine. Thakra et al. (2011) indicated that (71.33\% and 23.78\%) mother followed by elder sister the major source of informant. Kamath et al. (2013) also indicated that mother was the first sources of informant regarding menstruation in his samples. In case of absorbent used during menses 65 per cent girls used sanitary pads and remaining 35 per cent girls used cotton cloth in the residential school while 53.33 per cent used cotton cloth followed by 46.67 per cent used sanitary pads among non- residential school girls. Thakra et al. (2011) pointed out that (76.49\% and $23.51 \%$ ) used sanitary pad and cotton cloth. While regard to gap between the menses, it found that 36.67 per cent girls had 25-28 days and more than 32 days and only 26.67 per cent girls pointed out the gap of less than 24 days in residential school group. Whereas from non- residential school girls 48.33 per cent indicated the gap more than 32 days followed by 38.33 per cent girls had 25-28 days gap and other 13.33 per cent expressed the gap to be less than 24 days gap between menses. Allah et al. (2011) pointed out that majority of girls had normal menstrual cycle; some of them had their periods with longer than usual gaps. This could be attributed to some medical reason. In case of frequency of changing pads per day 78.33 per cent girls changed pads 3 times a day followed by 11.67 per cent girls changed only one time a day and remaining 10 per cent changed 2-3 times a day during menses in case of residential school, while from the non - residential school girls, 73.33 per cent once a day and remaining 11.67 per cent changed their pads 2-3 times per day. Sapkota et al. (2013) in his study found that about 41 per cent of changing pads more than three a day indicating heavy bleeding. A study conducted by Das et al. (2014) showed that majority of girls changed their pads twice or thrice a day.

The response related to know the menstrual problems among the residential and non residential school girls is shown in this Table 3. With respect to health problem during menstruation multiple responses were given by the school girls, 73.33 per cent girls suffered from stomachache followed by 15 per cent pointed out having backache then followed by 6.67 per cent had headache as well as loose motion and remaining 1.67 per cent indicated rashes (skin) in the residential school girls. While in case of non -residential school girls 76.67 per cent girls had stomachache followed by 16.67 per cent suffered from backache, 10 per cent girls had headache and only 1.67 per cent indicated having loose motion during their menstruation. None of them reported constipation, itching and swelling of feet and hands during menstruation. Adinma and Adinma (2008) found that dysmenorrhoea manifesting either as abdominal pain or as waist pain was more common among 
the respondents. In case of residential school girls, 75 per cent did not take rest during menstruation while 25 per cent felt like taking rest during their menses, while from non residential school girls 55 per cent didn't take rest while remaining 45 per cent felt the need for taking rest during their menses because they have to attend their regular household activities and restriction followed at home. Among residential school group 33.33 per cent girls felt irritable, unhappy, and moody during menses because they share their feeling with their friends/ peer group and 66.67 per cent felt normal during the menses whereas from the non-residential school girls 53.33 per cent felt irritable, unhappy and moody during menses and remaining 46.67 per cent felt normal during their menses. When asked about remaining absent for class during menses, 95 per cent said "No" and only 5 per cent said "Yes" from residential school girls. While from non- residential school 85 per cent said "No" and remaining 15 per cent said "Yes" for remaining absent in class during menses. . The reason in residential school girls may be because they have travel from home to school by bus or by walk. The distance they have to travel makes them stressful while in non-residential school girls they need not travel far a distance to reach their school to hostel, where both are in same premises. Pokhrel et al. (2014) indicated that about 91 per cent attended college during their menses in pre-test while there was significant increase in college attendance in post-test 96.7 per cent.

Care and management of menstruation among residential and non- residential school girls is pointed out in this Table 4. The girls from the residential school 40 per cent took bath once a day, whereas 60 per cent took bath twice a day during menses. In case of non-residential school girls 26.67 per cent had bath once a day while 73.33 per cent took bath twice a day. With regard to disposal method of residential school girls 80.95 per cent washed their cloths and dried outside, 14.28 per cent washed it and dried inside and only 4.76 per cent buried the cloth. In case of non-residential school girls, 71.42 per cent girls washed it and dried outside as well as washed it and dried inside and only 9.52 per cent burnt the cloth after use. The disposal methods of pads in residential school girls, 48.71 per cent washed and threw them in dustbin followed by 41.02 per cent flushed pads in lavatory after removing the plastic sheet and remaining 10.25 per cent flushed directly in lavatory. Whereas from non-residential school girls 50 per cent flushed pads in the lavatory after removing the plastic sheet followed by 35.71 per cent washed pads and then throw them in dustbin followed by 10.71 per cent burnt the pads and only 2.56 per cent flushed their pads directly in the lavatory. The girls were asked regarding management of emergency during menses by carrying additional pad/cloth in their school bags to manage emergency during menses, 16.67 per cent carried the pads whereas 83.33 per cent didn't carried pads in their bags in residential, while 33.33 per cent carried the pads because, to manage the emergency the non-residential girls carry additional pads in their bags sometimes it is not possible for a student to visit home and handle emergency and remaining 66.66 per cent didn't carried pads in their bags in non- residential school girls.

\section{CONCLUSIONS}

There was no difference and significant association found between the residential and non-residential school girls in case of knowledge on menstrual hygiene, while none of the girls had low knowledge. Mother was the major source of informant in both residential and non-residential school girls. The frequency of changing pad was more than three times and stomach ache was the major problem faced by the girls. Majority of the girls from residential and non-residential school did not miss the classes and only few took rest during their periods. While majority of them followed proper method of disposal of both cloth as well as sanitary pads. This is because in most of the schools, the girls are being educated about the menstrual hygiene and its management. But still there is a scope for improvement on giving more scientific knowledge about on menstrual hygiene. 


\section{REFERENCES}

1. Adinma, E. D. and Adinma, J. I. B, 2008, Perceptions and practices on menstruation amongst Nigerian secondary school girls. African .J. Reprod. Health. 12 (1): 74-83.

2. Agarwal, 2005, A new instrument (scale) for measuring socio-economic status of a family: Preliminary study. Indian. J. Comm. Med, 34 (4): 111-114.

3. Allah, A. S. E. and Elsabagh, M. E. E, 2011, Impact of health education intervention on knowledge and practice and menstruation among female secondary school student in Zagazig City. J. American Sci, 7(9): 737-747.

4. Chanda, K. and Itagi, S, 2016, knowledge on menstrual hygiene and health status of residential and non-residential school girls: Socio - Economic Status (SES). RA journal of applied research. 2(5): 458-467.

5. Chanda,K, Itagi,S. and Kulloli, D, 2016, Knowledge on menstrual hygiene : its interrelation with the components . Asia Pacific Journal of Research. 1(46): 16-20.

6. Das, A, Dasgupta, A, Biswas, A,Ghosal, A. and Sarkar, T , 2014, Knowledge and practices regarding menstrual management among women in a remote village of Eastern India. Int. J .Biol Med Res, 5(3): 4190-4196.

7. Kamath, R, Ghosh, D, Lena, A. and Chandrasekaran, V, 2013, a study on knowledge and practices regarding menstrual hygiene among rural and urban adolescent girls in Udupi Taluk. Manipal. India. Global .J. Med. Publ. Health. 2 (4):1-9.

8. Pokhrel, S, Mahantashetti, N, Amgolkar, M. and Devkota, N, 2014, Impact of health education on knowledge, attitude and practice regarding menstrual hygiene among pre university female students of a college located in urban area of Belgaum. J. Nurse. Health Sci, 3 (4): 38-44.

9. Sapkota, D, Sharma, D, Budhathoki, S. S, Khanal, V. K. and Pokharel, H. P, 2013, Knowledge and practices regarding menstruation among school girl's adolescents of rural Nepal. J. Kathmandu Med. College, 4 (5): 122-128.

10. Thakre, B. S, Sushama, S, Thakre, M, Nidhi Rathi, K. and Suresh, U, 2011, Menstrual Hygiene: knowledge and practice among adolescent school girls of Saoner. Nagpur District. J. Clinic. Diagno. Res, 5 (5): 1027-1033.

Table 1: Knowledge on Menstrual Hygiene of School Girls

\begin{tabular}{|c|c|c|c|c|c|}
\hline Sl. No. & $\begin{array}{c}\text { Knowledge on } \\
\text { Menstrual } \\
\text { Hygiene } \\
\end{array}$ & Residential $(n=60)$ & $\begin{array}{l}\text { Non-Residential } \\
\qquad(n=60)\end{array}$ & t-Value & $\chi^{2}$ \\
\hline 1 & Low & - & - & \multirow{4}{*}{0.83} & \multirow{4}{*}{$24.06^{*}$} \\
\hline 2 & Medium & $27(45.00)$ & $22(36.67)$ & & \\
\hline 3 & High & $33(55.00)$ & $38(63.33)$ & & \\
\hline & Mean $( \pm S D)$ & $55.71 \pm 3.48$ & $56.18 \pm 2.54$ & & \\
\hline
\end{tabular}

Figure in the parenthesis indicates percentage

* Significant at 0.05 level

Table 2: Qualitative Analysis Regarding History of Menstruation among Residential and Non- Residential School Girls

\begin{tabular}{|l|l|c|c|c|c|}
\hline \multirow{2}{*}{ Sl. No } & \multirow{2}{*}{ Particulars } & \multicolumn{2}{|c|}{ Residential (n=60) } & $\begin{array}{c}\text { Non -Residential } \\
(\mathbf{n = 6 0 )}\end{array}$ \\
\cline { 3 - 6 } & No & $\mathbf{\%}$ & NO & $\%$ \\
\hline A .Awareness of menarche before attainment \\
\hline \\
\hline
\end{tabular}




\begin{tabular}{|l|l|l|l|l|l|}
\hline & Mother & 43 & 71.66 & 38 & 63.33 \\
\hline & Elder sister & 17 & 28.33 & 22 & 36.67 \\
\hline C. Type of absorbent used during menses \\
\hline & Cotton cloth & 21 & 35.00 & 32 & 53.33 \\
\hline & Sanitary pads & 39 & 65.00 & 28 & 46.67 \\
\hline D. Gap between your menses \\
\hline \multicolumn{7}{|l|l|l|}{} \\
\hline & $<24$ days & 16 & 26.67 & 08 & 13.33 \\
\hline & $25-28$ days & 22 & 36.67 & 23 & 38.33 \\
\hline E Frequency of changing pads per day & 36.67 & 29 & 48.33 \\
\hline & 1 time & 07 & 11.67 & 09 & 15.00 \\
\hline & $2-3$ times & 06 & 10.00 & 07 & 11.67 \\
\hline & $>3$ times & 47 & 78.33 & 44 & 73.33 \\
\hline
\end{tabular}

Figure in the parenthesis indicates percentage

Multiple responses

Table 3: Qualitative Analysis Regarding Menstrual Problems Among Residential and Non- Residential School Girls

\begin{tabular}{|c|c|c|c|c|c|}
\hline \multirow[t]{2}{*}{ Sl. No. } & \multirow[t]{2}{*}{$\begin{array}{c}\text { Particulars } * \text { Multiple } \\
\text { Response }\end{array}$} & \multicolumn{2}{|c|}{$\begin{array}{l}\text { Residential } \\
\qquad(n=60)\end{array}$} & \multicolumn{2}{|c|}{$\begin{array}{c}\text { Non- } \\
\text { Residential } \\
(\mathbf{n}=60)\end{array}$} \\
\hline & & No & $\%$ & No & $\%$ \\
\hline \multicolumn{6}{|c|}{ A. Problems during menstruation } \\
\hline & Backache & 09 & 15.00 & 10 & 16.67 \\
\hline & Stomachache & 44 & 73.33 & 46 & 76.67 \\
\hline & Headache & 04 & 6.67 & 06 & 10 \\
\hline & Loose motion & 04 & 6.67 & 01 & 1.67 \\
\hline & Rashes (skin) & 01 & 1.67 & & \\
\hline \multicolumn{6}{|c|}{ B. Rest taken during menses } \\
\hline & Yes & 15 & 25.00 & 27 & 45.00 \\
\hline & No & 45 & 75.00 & 33 & 55.00 \\
\hline \multicolumn{6}{|c|}{ C. Feeling of irritability/unhappy moody during menses } \\
\hline & Yes & 20 & 33.33 & 32 & 53.33 \\
\hline & No & 40 & 66.67 & 28 & 46.67 \\
\hline \multicolumn{6}{|c|}{ D. Absenteeism for class during menses } \\
\hline & Yes & 03 & 5.00 & 09 & 15.00 \\
\hline & No & 57 & 95.00 & 51 & 85.00 \\
\hline
\end{tabular}

Figure in the parenthesis indicates percentage

Multiple responses

Table 4: Qualitative Analysis Regarding Care and Management of Menstruation Among Residential and Non- Residential School Girls

\begin{tabular}{|c|c|c|c|c|c|}
\hline \multirow{2}{*}{ Sl. No. } & \multirow{2}{*}{$\begin{array}{l}\text { Particulars of Care and } \\
\text { Management of Menses }\end{array}$} & \multicolumn{2}{|c|}{ Residential } & \multicolumn{2}{|c|}{ Non- Residential } \\
\hline & & No & $\%$ & No & $\%$ \\
\hline $\mathrm{A}$ & Bathing pattern during menses & \multicolumn{2}{|l|}{$(n=60)$} & \multicolumn{2}{|l|}{$(n=60)$} \\
\hline & 1 time & 24 & 40.00 & 16 & 26.67 \\
\hline & 2 times & 36 & 60.00 & 44 & 73.33 \\
\hline \multirow[t]{5}{*}{$\mathrm{B}$} & Disposal of the cloth & \multicolumn{2}{|l|}{$(\mathrm{n}=21)$} & \multicolumn{2}{|l|}{$(n=32)$} \\
\hline & Wash and dry outside & 17 & 80.95 & 15 & 46.87 \\
\hline & Wash and dry inside & 03 & 14.28 & 15 & 46.87 \\
\hline & Burn & & & 02 & 6.25 \\
\hline & Burry & 01 & 4.76 & & \\
\hline
\end{tabular}




\begin{tabular}{|c|c|c|c|c|c|}
\hline $\mathrm{C}$ & Disposal of the sanitary pad & \multicolumn{2}{|c|}{$(n-39)$} & \multicolumn{2}{|c|}{$(n-28)$} \\
\hline & Wash and throw it in dustbin & 19 & 48.71 & 10 & 35.71 \\
\hline & Flush it in the lavatory & 04 & 10.25 & 01 & 3.58 \\
\hline & $\begin{array}{l}\text { Flush it in the lavatory after } \\
\text { removing the plastic sheet }\end{array}$ & 16 & 41.02 & 14 & 50.00 \\
\hline & Burn & & & 03 & 10.71 \\
\hline $\mathrm{D}$ & $\begin{array}{l}\text { Management emergency during } \\
\text { menses }(n=60)\end{array}$ & \multicolumn{2}{|l|}{$(\mathrm{n}=60)$} & \multicolumn{2}{|l|}{$(n=60)$} \\
\hline & Yes & 10 & 16.67 & 20 & 33.33 \\
\hline & No & 50 & 83.33 & 40 & 66.66 \\
\hline
\end{tabular}

Figure in the parenthesis indicates percentage

Multiple responses 
